BMJ Open

Sport \&

Exercise

Medicine

\title{
In-match physical demands on elite Japanese rugby union players using a global positioning system
}

\author{
Hayato Yamamoto (D) , ${ }^{1}$ Masanori Takemura,${ }^{2}$ Junta Iguchi, ${ }^{3}$ Misato Tachibana, \\ Junzo Tsujita, ${ }^{4}$ Tatsuya Hojo ${ }^{1}$
}

To cite: Yamamoto $\mathrm{H}$, Takemura M, Iguchi J, et al. In-match physical demands on elite Japanese rugby union players using a global positioning system. BMJ Open Sport \& Exercise Medicine 2020;6:e000659. doi:10.1136/ bmjsem-2019-000659

Accepted 6 December 2019
Check for updates

(C) Author(s) (or their employer(s)) 2020. Re-use permitted under CC BY-NC. No commercial re-use. See rights and permissions. Published by BMJ.

${ }^{1}$ Graduate School of Health \& Sports Science, Doshisha University, Kyoto, Japan ${ }^{2}$ Ichihashi Clinic, Kobe, Japan ${ }^{3}$ Department of Health and Sports Sciences, Kyoto University of Advanced Science, Kameoka, Japan

${ }^{4}$ Institute of Health and Sports Medicine Science, Osaka, Japan

Correspondence to Hayato Yamamoto; trainer_life_22@yahoo.co.jp

\section{ABSTRACT}

Objectives Our aim of this study was to quantify the physical demands of elite rugby union players by each position as a step towards designing position-specific training programme using a Global Positioning System/ accelerometer system.

Methods This study was performed as a retrospective observational study. Data were obtained from 45 official matches. The sample size used for the analysis was 298. The per-match total distances, accelerations and impacts were calculated and statistically compared for the forwards and backs and for individual positions.

Results Total distances for the forwards and backs were $5731.1 \pm 507.8$ and $6392.1 \pm 646.8 \mathrm{~m}$, respectively. The high-velocity running distances ( $>18.0 \mathrm{~km} /$ hour) covered by the forwards and backs were $317.4 \pm 136.9$ and $715.0 \pm 242.9 \mathrm{~m}$, respectively. The number of accelerations $\left(>1.5 \mathrm{~m} / \mathrm{s}^{2}\right)$ for the forwards and backs were $76.3 \pm 18.9$ and $100.8 \pm 19.6$ times, respectively, and the number of high impacts ( $>10 \mathrm{~g}$ ) were $48.0 \pm 46.9$ and $35.6 \pm 28.3$ times for the forwards and backs, respectively. All characteristics were significantly different between the forwards and backs $(p<0.05)$. The per-position characteristics were also calculated. Within the backs, scrum half (SH) and wingers (WTBs) covered high-velocity running significantly higher distance than fly-half (SH $d=2.571$, WTBs $d=1.556$ ) and centres (SH $d=1.299$, WTBs $d=0.685)(p<0.05)$.

Conclusion By clarifying the physical demands according to the positions, it will be possible to create optimised position-specific training programmes.

\section{INTRODUCTION}

Player movements during a rugby union match consist of intermittent bouts of intense motion, requiring explosive force exertion for high-velocity activities, such as sprinting, tackling and scrummaging, with breaks comprising low-intensity activity, such as walking and jogging. ${ }^{1-3}$ Previously, research on the physical demands on players during a rugby union match was often analysed using video-based time-motion analysis. Austin et al reported on the distance and speed of travel during a match, while Eaton and George reported on tackling and scrum

\section{What are the new findings?}

- The physical demands of elite rugby union players in a match in Japan were revealed.

- This finding allows comparison with overseas teams.

- Not only tha data of classification of forwards and backs, but also the distance traveled, acceleration, and impact of each position became clear.

- The idea of developing strength and conditioning programme based on the results was presented.

management. ${ }^{2}$ 4-7 However, methods using video-based time-motion analysis in rugby union can be unreliable because they are vulnerable to the subjectivity of the evaluator/ analyst. ${ }^{89}$ Also, video-based time-motion analysis cannot evaluate contacts such as impacts.

To improve the objectivity, Global Positioning Systems (GPS) and accelerometers have been used to analyse in-match physical demands. ${ }^{10-12}$ Currently, there are reports on the reliability and validity of GPS units. ${ }^{11-14}$ GPS units with built-in accelerometers can obtain data reliably and in real-time, unlike video-time analyses, and have thus been commonly used for analysing physical demands in team sports such as soccer, ${ }^{15}{ }^{16}$ field hockey, ${ }^{17} 18$ rugby league ${ }^{1920}$ and Australian Football League. ${ }^{21} 22$ On the other hand, there are few studies using GPS to analyse physical demands of contemporary rugby union play compared with other sports (soccer, rugby league and Australian football league). ${ }^{823-26}$ In addition, even in the reported research, there are issues such as the lack of statistical analysis due to the small sample size, and not being analysed by individual positions in the classification of forwards and backs. Such analyses are insufficient as a study of physical demands.

Notably, there are few reports detailing the physical demands during elite rugby union matches in Japan. ${ }^{27}$ Therefore, this study was designed to analyse the physical demands of elite rugby union players in Japan during a 
match using a GPS/accelerometer system. We analysed the raw data from players who played full matches and calculated the physical demands in terms of distance travelled, accelerations and impacts. We also statistically analysed these calculations for the forward and back groups and for each individual position. We believe that these data will enable sports scientists and strength and conditioning coaches to develop improved training programme that can improve player performance and reduce the risk of injuries related to non-optimal training.

Previous studies have shown physical demands in the forwards and backs classifications, but each position is assumed to have unique characteristics beyond the forwards and backs classifications. Thus, our aim of this study was to quantify the movement (or physical) demands of elite union players by forwards and backs as well as each position using a GPS/accelerometer system. Then, by understanding of the movement (or physical) demands, it may provide valuable insight into an effective strength and conditioning training programme for each position based on game-based training approaches. We hypothesised that backs would move in faster speed zones and their mileage would be relatively longer than forwards. On the other hand, forwards would have heavier body loads because of spending more time in slower and high-intensity activities such as scrums compared with backs.

\section{METHODS \\ Design}

Data were collected using GPS units with built-in accelerometers during official matches from one team belonging to the Japan Rugby top league. The team played 14 matches in 2013 (4 wins-10 losses record), 16 matches in 2014 (6 wins-10 losses) and 15 matches in 2015 (4 wins-10 losses-one draw), that is, a total of 45 matches (14 wins-30 losses-one draw) over three seasons. As the Japan Rugby top league is the pre-eminent rugby competition in Japan, the data collected for this study can be said to be that of elite rugby union. We analysed the raw data from players who played full matches over three seasons and calculated the physical demands in terms of distance travelled, accelerations and impacts. We then statistically analysed these calculations for the forward and back groups and for each individual position.

\section{Participants}

Data were obtained from one team belonging to the Japan Rugby top league. The participants were 15 starting members in each match $(n=675)$. However, we excluded those players who did not play the full $80 \mathrm{~min}$ duration (ie, those who underwent substitution for any reason). A total of 298 subjects (forwards: age $27.9 \pm 3.0$ years, height $183.1 \pm 6.3 \mathrm{~cm}$ and body mass $100.3 \pm 7.2 \mathrm{~kg}$, backs: age $27.7 \pm 2.7$ years, height $173.9 \pm 7.8 \mathrm{~cm}$ and body mass $84.2 \pm 11.8 \mathrm{~kg}$ ) were used in the sample analysis.

GPS unit data from the matches were collected from dedicated teams. The objectives and possible limitations of the study were explained to potential subjects. Written consent was obtained from all subjects prior to enrolment. This research was done without patient involvement.

\section{GPS analysis}

We used GPS units (SPI Pro X; GPSports Systems, Canberra, Australia) with built-in accelerometers with sampling frequencies of 5 and $100 \mathrm{~Hz}$. The GPS unit was placed on the upper middle back between the scapulae of the subject using special protective vests recommended by the manufacturer. Previous studies have shown that GPS units have acceptable reliability and validity to measure movement. ${ }^{11-14}$ Previous studies have shown the reliability of GPS units using intraclass correlation coefficient, and the results show high reliability from 0.98 to $0.99 .^{28}$

The GPS system and accompanying software (Team AMS; GPSports Systems) can measure the total distance, distance travelled within velocity ranges ('zones'), acceleration/deceleration, impact (using the accelerometer) and heart rate when synchronised with a heart rate monitor. ${ }^{29}$ Distance (total distance and distance travelled within velocity zones), acceleration and impact were used for analysing physical demands during a match.

\section{Distance travelled}

The total distance travelled between 'kickoff' and 'fulltime' was measured as the total distance, including both when the ball was in and out of play. The out-ofplay distance was included because rugby uses a running clock, and positioning for the next play (quickly) is as important as that when the ball is in play. ${ }^{29} 30$

Total distance was subdivided into total distance/ velocity by binning velocity into three zones (ranges): speed zone SZ-1 (0-12.0 km/hour, SZ-2 (12.1-18.0 km/ hour) and SZ-3 (>18.0 km/hour). Both the absolute value of the distance travelled in each zone and percentage of the total distance were calculated. The threshold of the speed zone was set based on the previous research of rugby union. ${ }^{8}$

Mean velocity was calculated by dividing the total distance by $80 \mathrm{~min}$.

\section{Accelerations}

Accelerations were calculated from the GPS data as velocity per unit time $\left(\mathrm{m} / \mathrm{s} / \mathrm{s}, \mathrm{ie}, \mathrm{m} / \mathrm{s}^{2}\right)$ and binned into three zones as follows: acceleration zone (AZ)-1, 1.5-2.0 $\mathrm{m} / \mathrm{s}^{2} ;$ AZ-2, $2.0-2.5 \mathrm{~m} / \mathrm{s}^{2} ; \mathrm{AZ}-3,>2.5 \mathrm{~m} / \mathrm{s}^{2}$. The threshold of the $\mathrm{AZ}$ was set based on the previous research of rugby union. ${ }^{8}$

\section{Impacts}

Impacts were calculated from the accelerometer data. The three-dimensional (triaxial) linear accelerometric values were collected and transformed into gravity $(\mathrm{g})$ by dividing the raw value by $9.81 \mathrm{~m} / \mathrm{s}^{2}$. Impacts were binned into two impact zones (IZ): IZ-1 (8.1-10 g) and IZ-2 (>10 $\mathrm{g})$. 


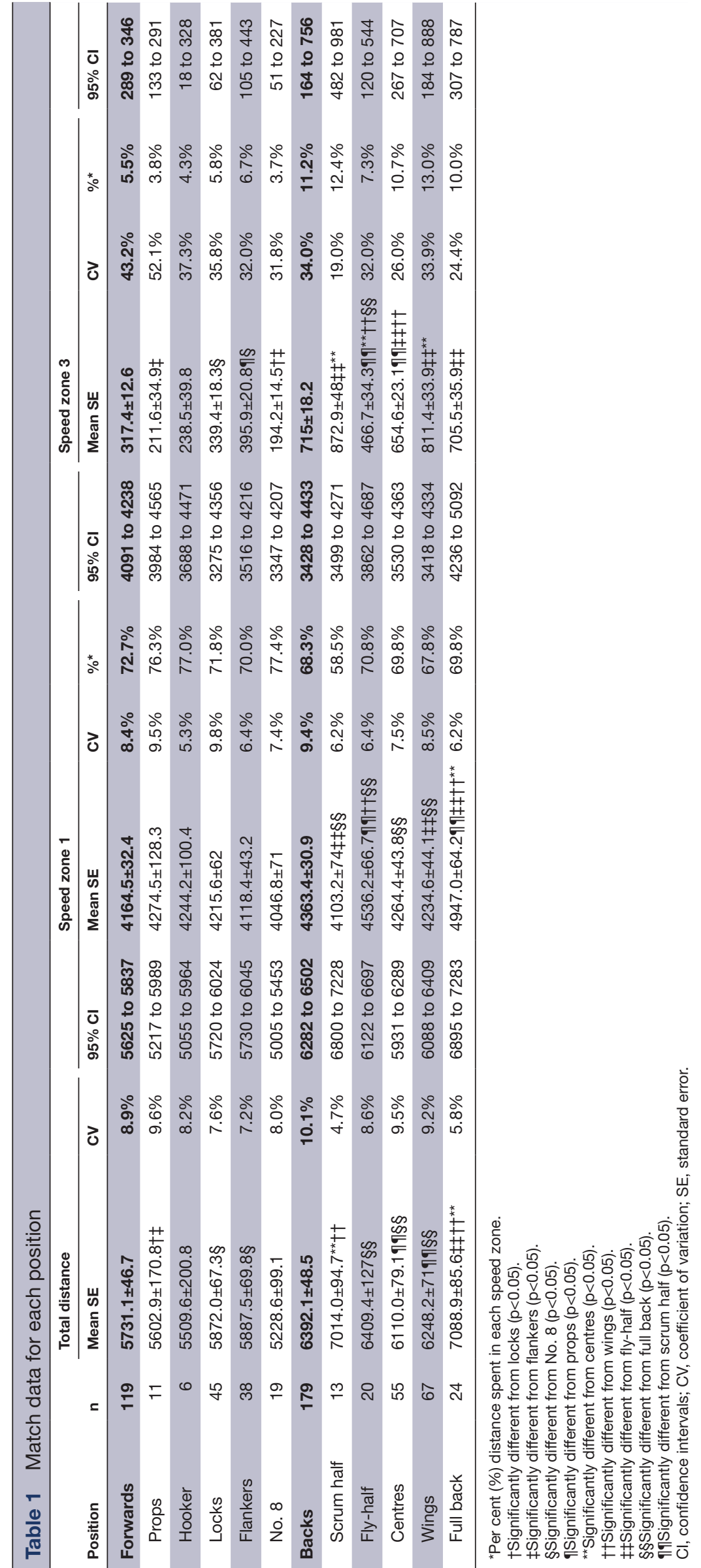



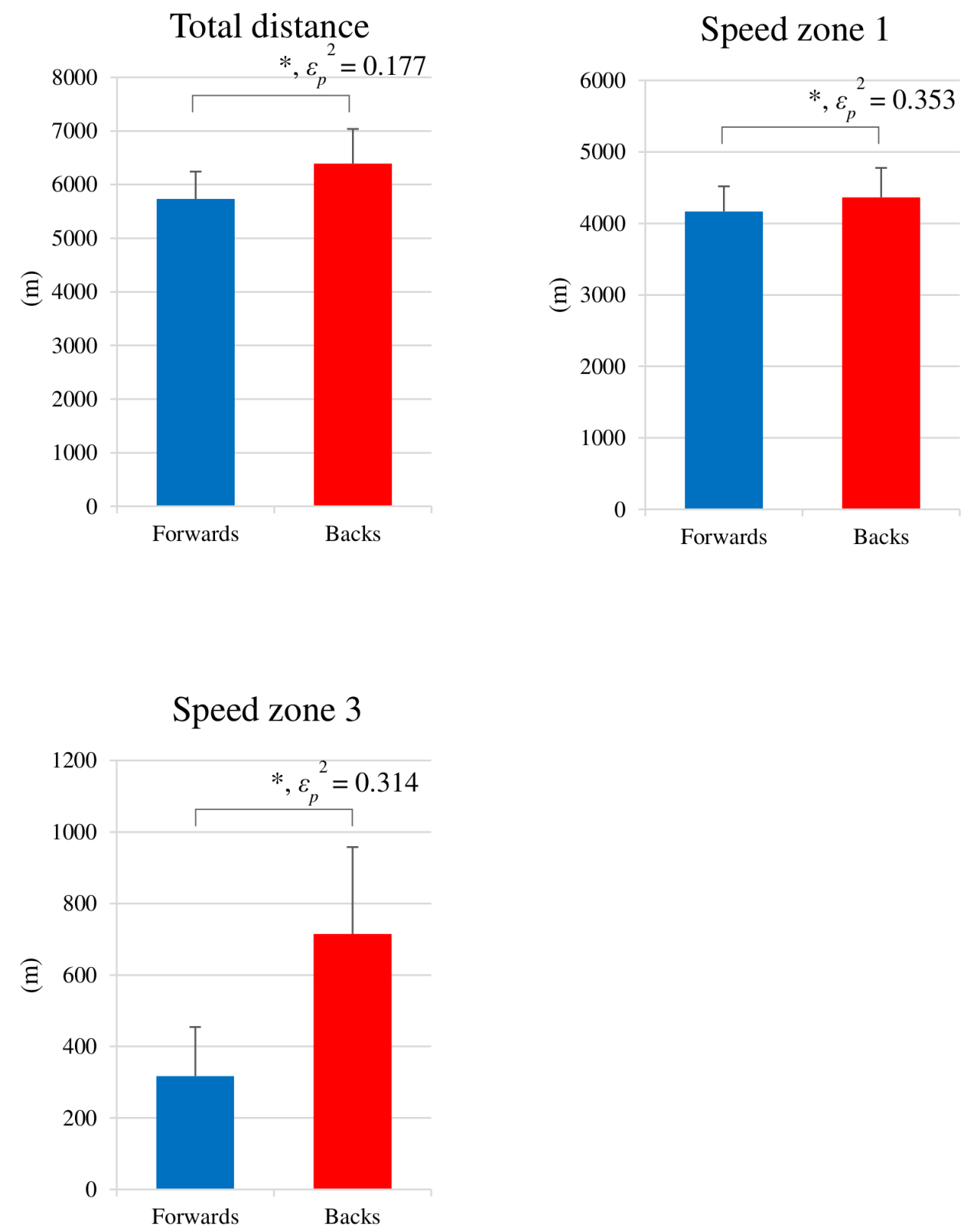

Figure 1 Match data per position (forwards and backs). *Significantly different $(p<0.05)$.

\section{Classification of positions}

Rugby union consists of 10 positions: five forwards positions (props (PRs), hooker (HO), locks (LOs), flankers (FLs), eight-man/number eight (No. 8)) and five backs positions (scrum-half $(\mathrm{SH})$, fly-half $(\mathrm{FH})$, centres (CTBs), wings (WTBs) and full back (FB)). Analyses were performed on the combined data of the forwards or backs positions as well as on each individual position.

\section{Statistical analysis}

Data were delineated as mean \pm SE. The coefficient of variation (CV) was also calculated to compare the variability of the data for each parameter.

First, the homogeneity of variance was tested using Bartlett's test. As most did not satisfy these conditions, non-parametric Kruskal-Wallis hypothesis test was used to compare variables between forwards and backs as well as among individual positions. When differences were significant, multiple comparisons were made using SteelDwass test. Epsilon partial squared $\left(\varepsilon_{p}^{2}\right)$ and Cohen's $d$ were calculated as effect size. Statistical significance was set at $\mathrm{p}<0.05$. ' $\mathrm{R}$ ' was used for statistical analysis.

Samples measured in this study were similar to those in previous researches, and players participated in multiple matches. The methodology used was adopted from previous research. ${ }^{23}$

\section{RESULTS}

\section{Distance travelled}

The total distance covered per match by the forwards and backs was significantly different $\left(\mathrm{p}<0.05, \varepsilon_{p}^{2}=0.177\right)$ (table 1 and figure 1). Of the forwards, LOs $(d=1.484)$ and FLs $(d=1.559)$ covered significantly longer distances than 


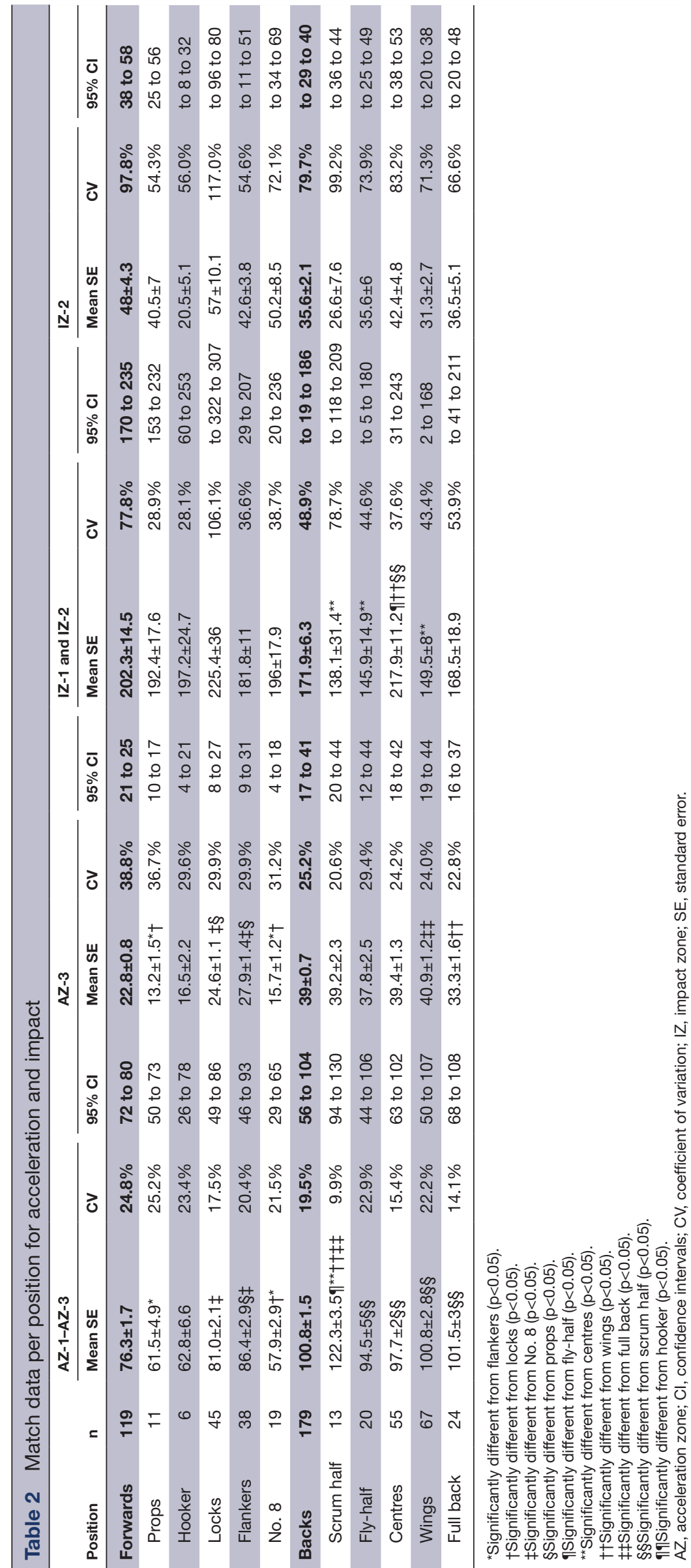


Acceleration zone 1 to 3

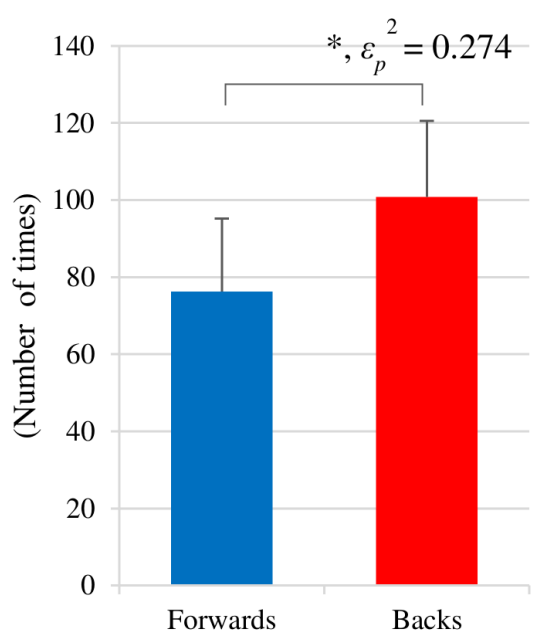

Impact zone $1 \& 2$

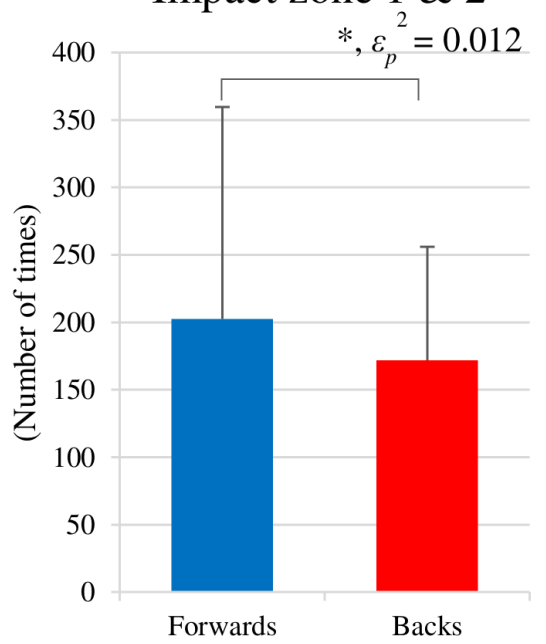

Acceleration zone 3

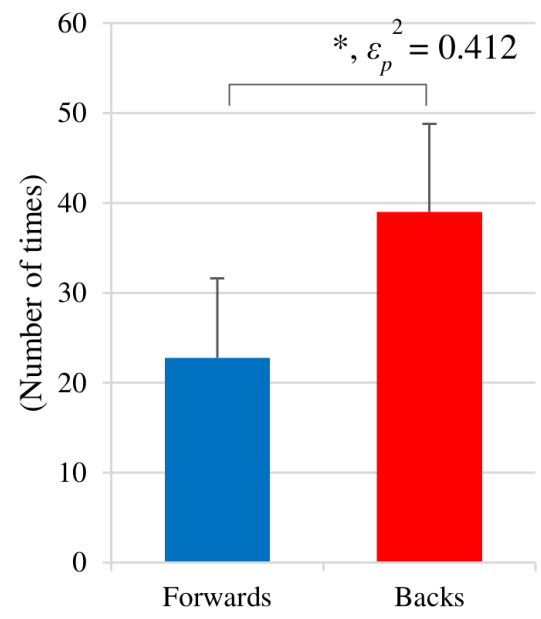

Impact zone 2

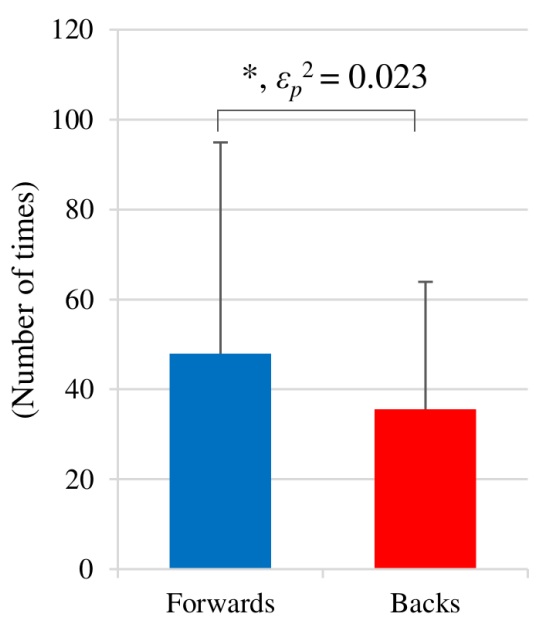

Figure 2 Match data per position (forwards and backs). *Significantly different $(p<0.05)$.

No. 8 ( $\mathrm{p}<0.05$, respectively). Of the backs, $\mathrm{SH}$ covered significantly longer distances than WTBs $(d=1.633)$ and CTBs $(d=1.915) \quad(\mathrm{p}<0.05)$. In addition, the distance covered by $\mathrm{FB}$ was significantly longer than that by $\mathrm{FH}$ $(d=1.395)$, WTBs $(d=1.680)$ and CTBs $(d=1.945)(\mathrm{p}<0.05)$ (table 1).

The distances covered in SZ-3 by the forwards and backs were also significantly different $\left(\mathrm{p}<0.05, \varepsilon_{p}^{2}=0.314\right)$ (table 1 and figure 1). Of the forwards, LOs (PRs $d=1.101$, No. $8 d=1.507$ ) and FLs (PRs $d=1.551$, No. $8 d=2.023$ ) covered significantly longer distances than PRs and No. $8(\mathrm{p}<0.05)$. Of the backs, significant differences were found between $\mathrm{SH}$ and WTBs compared with $\mathrm{FH}$ (SH $d=2.571$, WTBs $d=1.556$ ) and CTBs (SH $d=1.299$, WTBs $d=0.685$ ), and between CTBs and FB compared with FH $(p<0.05)$, with the former being greater than the latter in both the cases (table 1 ).

The backs covered significantly longer distances in SZ-1 than the forwards $\left(\mathrm{p}<0.05, \varepsilon_{p}^{2}=0.353\right)$ (table 1 and figure 1). The forwards' results did not differ significantly according to position, but $\mathrm{FH}$ and $\mathrm{FB}$ covered significantly longer distances than $\mathrm{SH}(\mathrm{FH} d=1.580, \mathrm{FB}$ $d=2.980)$, WTBs (FH $d=0.422, \mathrm{FB} d=2.133)$ and CTBs $(\mathrm{FH}$ $d=0.887, \mathrm{FB} d=2.169)(\mathrm{p}<0.05) \quad($ table 1$)$.

The CV of the total distance showed a small value; moreover, it indicated a large value as the moving speed increased (table 1).

\section{Acceleration}

The number of accelerations for the forwards and backs was significantly different $\left(\mathrm{p}<0.05, \varepsilon_{p}^{2}=0.274\right)$ (table 2 and figure 2). Of the forwards, LOs (PRs $d=1.315$, No. $8 d=1.731$ ) and FLs (PRs $d=1.505$, No. $8 d=1.868$ ) were required to accelerate many more times than that by PRs and No. 8; SH (FH $d=1.591$, CTBs $d=1.806$, WTBs $d=1.196, \mathrm{FB} d=1.568$ ) had to accelerate many times than that by other backs $(\mathrm{p}<0.05)$ (table 2$)$. 
Table 3 Application to training for each forwards position

\begin{tabular}{|c|c|c|c|}
\hline Position & Results & Physical demands during the match & Application to training \\
\hline $\begin{array}{l}\text { Props } \\
\text { (PRs) }\end{array}$ & $\begin{array}{l}\text { Number of impact: high } \\
\text { (compared with backs ) }\end{array}$ & $\begin{array}{l}\text { Ability to repeat contacts (contact fitness). } \\
\text { Physical to win at contact (increase of } \\
\text { skeletal muscle mass, improvement of } \\
\text { maximum strength and power). }\end{array}$ & $\begin{array}{l}\text { Focus on contact fitness training compared } \\
\text { with backs. } \\
\text { Weight training aimed at weight gain due to } \\
\text { muscle hypertrophy compared with backs. }\end{array}$ \\
\hline $\begin{array}{l}\text { Hooker } \\
(\mathrm{HO})\end{array}$ & $\begin{array}{l}\text { Number of impact: high } \\
\text { (compared with backs ) }\end{array}$ & $\begin{array}{l}\text { Ability to repeat contacts (contact fitness). } \\
\text { Physical to win at contact (increase of } \\
\text { skeletal muscle mass, improvement of } \\
\text { maximum strength and power). }\end{array}$ & $\begin{array}{l}\text { Focus on contact fitness training compared } \\
\text { with backs. } \\
\text { Weight training aimed at weight gain due to } \\
\text { muscle hypertrophy compared with backs. }\end{array}$ \\
\hline \multirow[t]{2}{*}{$\begin{array}{l}\text { Locks } \\
\text { (LOs) }\end{array}$} & $\begin{array}{l}\text { AZ-3 and SZ-3: high } \\
\text { (compared with PRs and } \\
\text { HO ) }\end{array}$ & $\begin{array}{l}\text { Ability to repeat large acceleration and } \\
\text { move at high speed (such as sprint). }\end{array}$ & $\begin{array}{l}\text { Focus on speed and agility training and } \\
\text { repeated sprint ability training compared } \\
\text { with PRs and } \mathrm{HO} \text {. }\end{array}$ \\
\hline & $\begin{array}{l}\text { Number of impact: } \\
\text { high (compare within } \\
\text { forwards ) }\end{array}$ & $\begin{array}{l}\text { Ability to repeat contacts (contact fitness). } \\
\text { Physical to win at contact (increase of } \\
\text { skeletal muscle mass, improvement of } \\
\text { maximum strength and power). }\end{array}$ & $\begin{array}{l}\text { Compared with other forwards, focus more } \\
\text { on contact fitness training. }\end{array}$ \\
\hline \multirow[t]{2}{*}{$\begin{array}{l}\text { Flankers } \\
\text { (FLs) }\end{array}$} & $\begin{array}{l}\text { AZ-3 and SZ-3: high } \\
\text { (compared with PRs and } \\
\mathrm{HO} \text { ) }\end{array}$ & $\begin{array}{l}\text { Ability to repeat large acceleration and } \\
\text { move at high speed (such as sprint). }\end{array}$ & $\begin{array}{l}\text { Focus on speed and agility training and } \\
\text { repeated sprint ability training compared } \\
\text { with PRs and } \mathrm{HO} \text {. }\end{array}$ \\
\hline & $\begin{array}{l}\text { Number of impact: high } \\
\text { (compared with backs ) }\end{array}$ & $\begin{array}{l}\text { Ability to repeat contacts (contact fitness). } \\
\text { Physical to win at contact (increase of } \\
\text { skeletal muscle mass, improvement of } \\
\text { maximum strength and power). }\end{array}$ & $\begin{array}{l}\text { Focus on contact fitness training compared } \\
\text { with Backs. } \\
\text { Weight training aimed at weight gain due to } \\
\text { muscle hypertrophy compared with backs. }\end{array}$ \\
\hline No. 8 & $\begin{array}{l}\text { Number of impact: high } \\
\text { (compared with backs ) }\end{array}$ & $\begin{array}{l}\text { Ability to repeat contacts (contact fitness). } \\
\text { Physical to win at contact (increase of } \\
\text { skeletal muscle mass, improvement of } \\
\text { maximum strength and power). }\end{array}$ & $\begin{array}{l}\text { Focus on contact fitness training compared } \\
\text { with backs. } \\
\text { Weight training aimed at weight gain due to } \\
\text { muscle hypertrophy compared with backs. }\end{array}$ \\
\hline
\end{tabular}

AZ, acceleration zone; SZ, speed zone.

The number of accelerations in AZ-3 was significantly higher for the backs than for the forwards $(p<0.05$, $\left.\varepsilon_{p}^{2}=0.412\right)$ (table 2). Of the forwards, LOs (PRs $d=1.834$, No. $8 d=1.428$ ) and FLs (PRs $d=2.158$, No. $8 d=1.787$ ) had significantly higher number of accelerations than PRs and No. $8(\mathrm{p}<0.05)$; of the backs, FB had significantly lower accelerations than WTBs $(\mathrm{FB} d=0.867) \quad(\mathrm{p}<0.05)$ (table 2).

\section{Impacts}

The number of impacts was significantly higher for the forwards than for the backs $\left(\mathrm{p}<0.05, \varepsilon^{2}=0.012\right)$ (table 2 and figure 2). There were no significant differences among the forwards, whereas CTBs had a significantly higher number of impacts than SH (CTBs $d=0.830$ ), FH (CTBs $d=0.973)$ and WTBs (CTBs $d=0.926) \quad(\mathrm{p}<0.05)$ (table 2).

For the high-force (IZ-2) zone, there was a significant difference between the forwards and backs $(p<0.05$, $\varepsilon_{p}^{2}=0.023$ ) (table 2 and figure 2) but none between any individual positions (table 2).

\section{DISCUSSION}

This study analysed the physical demands of elite rugby union players in Japan based on data from a team belonging to Japan Rugby top league. Knowledge of the physical demands during a match can help sports scientists and strength and conditioning coaches create optimised training programme aimed at improving competitiveness and possibly avoiding injury.

We only analysed the players who played for the complete duration of the match $(80 \mathrm{~min})$ without being substituted. In previous research, data for substituted players were included by extrapolating full match data from the partial-match ones. ${ }^{7}$ However, because this technique cannot account for fatigue or performance degradation during an actual match, they are not likely to be an accurate evaluation of the physical demands of a full match. In addition, previous research has stated that the appropriateness of extrapolating data to provide full match data information is questionable. ${ }^{23}$

As hypothesised, in terms of the total distance travelled and speed (mean velocity over the $80 \mathrm{~min}$ match), the forwards showed significantly lower values than the backs $(5731$ and $6392 \mathrm{~m}, 71.6$ and $79.9 \mathrm{~m} / \mathrm{min}$, respectively). The differences averaged to $660 \mathrm{~m}$ and $8 \mathrm{~m} /$ min per match. In terms of SZ-3, backs covered $715 \mathrm{~m}$ and forwards covered $317 \mathrm{~m}$; the per cent SZ-3 for the backs was $11.2 \%$ and for the forwards was $5.5 \%$. The total distance is a measure of the overall amount of exercise, whereas SZ-3 indicates exercise intensity. Therefore, our data suggested that the backs had higher load and intensity during a match. Notably, in SZ-1, the significant 
Table 4 Application to training for each backs position

\begin{tabular}{|c|c|c|c|}
\hline Position & Results & Physical demands during the match & Application to training \\
\hline \multirow[t]{2}{*}{$\begin{array}{l}\text { Scrum half } \\
\text { (SH) }\end{array}$} & $\begin{array}{l}\text { Total distance } \\
\text { Number of accelerations: } \\
\text { high (compared with all } \\
\text { positions) }\end{array}$ & $\begin{array}{l}\text { Running fitness ability that can cover many } \\
\text { travel distances during match. } \\
\text { Resistance of lower limbs that can } \\
\text { withstand muscle cramps caused by many } \\
\text { travel distances and many acceleration } \\
\text { times. }\end{array}$ & $\begin{array}{l}\text { Focus on running fitness training } \\
\text { among all positions. }\end{array}$ \\
\hline & $\begin{array}{l}\text { AZ-3 and SZ-3: high } \\
\text { (compared with all positions) }\end{array}$ & $\begin{array}{l}\text { Ability to repeat large acceleration and } \\
\text { move at high speed (such as sprint). }\end{array}$ & $\begin{array}{l}\text { Focus on speed and agility training } \\
\text { and repeated sprint ability training. }\end{array}$ \\
\hline $\begin{array}{l}\text { Fly-half } \\
(\mathrm{FH})\end{array}$ & $\begin{array}{l}\text { Total distance and SZ- } \\
\text { 3: high (compared with } \\
\text { forwards) }\end{array}$ & $\begin{array}{l}\text { Running fitness that can cover many travel } \\
\text { distances during match. } \\
\text { Ability to repeat high speed movement } \\
\text { (repeated sprint ability). }\end{array}$ & $\begin{array}{l}\text { Focus on running fitness training } \\
\text { compared with backs. } \\
\text { Focus on speed and agility training } \\
\text { and repeated sprint ability training } \\
\text { compared with forwards. }\end{array}$ \\
\hline $\begin{array}{l}\text { Centres } \\
\text { (CTBs) }\end{array}$ & $\begin{array}{l}\text { Number of impact: high } \\
\text { (compare within backs) }\end{array}$ & $\begin{array}{l}\text { Ability to repeat contacts (contact fitness). } \\
\text { Physical to win at contact (increase of } \\
\text { skeletal muscle mass, improvement of } \\
\text { maximum strength and power). }\end{array}$ & $\begin{array}{l}\text { Compared with other backs, focus on } \\
\text { contact fitness training. } \\
\text { Weight training aimed at weight gain } \\
\text { due to muscle hypertrophy compared } \\
\text { with other backs. }\end{array}$ \\
\hline $\begin{array}{l}\text { Wings } \\
\text { (WTBs) }\end{array}$ & $\begin{array}{l}\text { SZ-3: high (compared with } \\
\text { all positions) }\end{array}$ & $\begin{array}{l}\text { Improvement of maximum speed. } \\
\text { Improvement of repeated sprint ability. }\end{array}$ & $\begin{array}{l}\text { Focus on speed } \& \text { agility training and } \\
\text { repeated sprint ability training. }\end{array}$ \\
\hline $\begin{array}{l}\text { Full back } \\
\text { (FB) }\end{array}$ & $\begin{array}{l}\text { Total distance: high } \\
\text { (compared with all positions) }\end{array}$ & $\begin{array}{l}\text { Running fitness that can cover many travel } \\
\text { distances during match. } \\
\text { Resistance of lower limbs that can } \\
\text { withstand muscle cramps caused by many } \\
\text { travel distances and many acceleration } \\
\text { times. }\end{array}$ & $\begin{array}{l}\text { Focus on running fitness training } \\
\text { among all positions. }\end{array}$ \\
\hline
\end{tabular}

AZ, acceleration zone; SZ, speed zone.

difference in the distance travelled was not present when the percentage of the total distance was considered. Thus, the difference in endurance-related and activity-related physical demands between forwards and backs during a match is related to the amount of SZ-3. However, SZ-3 was uniformly defined for all positions, although forwards are likely to have a lower maximum speed and require a greater effort to reach SZ-3. Adjusting the speed zones for position and taking maximum speed into account would enable a more detailed analysis of exercise intensity.

When comparing the results of previous studies of European professional teams with those of this study, the total distance is effectively equivalent. ${ }^{23}{ }^{25}$ Despite Japan's national team holding a lower rank than other national teams competing in the rugby World Cup, the total work levels are very similar. This seems to indicate that it is impossible to sufficiently evaluate team ability by work alone. Thus, accelerations and impacts were also analysed.

Backs recorded significantly higher total and AZ-3specfic accelerations than the forwards. In particular, AZ-3, which mainly represents sprints, was considerably different $(0.29$ and 0.49 bouts/min for forwards and backs, respectively). Thus, the backs are required to perform intense accelerations more often during a match. It should be noted that the maximal acceleration possible for the forwards is likely to be lower than that for the backs, which could have resulted in a bias in the results. ${ }^{8}$

Impacts, in contrast to accelerations, resulted in a significantly higher result for the forwards than for the backs which is consistent with our hypothesis. Impacts occur when a tackle is made and when any physical shock is applied to the body. For instance, situations related to competition for the ball, such as breakdowns and contact with the ground, also register as impacts. As expected, the forwards are required to absorb a high number of impact loads. Thus, it is necessary for forwards to increase their fitness so that players can repeat contacts. In addition, it is necessary to increase muscle hypertrophy for players to prevent injury from high-impact collision.

Within the forwards, distance of SZ-3 and the number of times of AZ-3 for LOs and FLs were significantly higher than those for the other positions. Our data indicate that LOs and FLs are required to increase their maximum speed and repeat-sprint ability compared with the other forwards.

Notably, the data for No. 8 was different than those from previous study. ${ }^{23}$ In the previous study, No. 8 was similar to LOs in terms of total distance; however, in the present study, No. 8 had lower total distance than LOs. The No. 8 data for this study were obtained from players with relatively heavy weight (over $120 \mathrm{~kg}$ ). Therefore, the No. 8 data in this study may have been greatly influenced 
by the characteristics of that specific player. In order to measure the physical demands of No. 8, additional research is needed with a larger player population to better clarify the results.

In addition, LOs had higher impact values than those of the other forward positions for IZ-2 (57 times). Thus, LOs should be considered to be in a position that requires above-average physical strength (relative to other forwards as well as backs) to repeatedly engage in contact while maintaining the sprinting ability mentioned earlier.

Within the backs, the total distance by $\mathrm{SH}$ and $\mathrm{FB}$ was $\geq 7000 \mathrm{~m}$, which is approximately 600-900 $\mathrm{m}$ higher than that for other backs. The CV of the total distance by $\mathrm{SH}$ and $\mathrm{FB}$ was approximately $5 \%$, which was lower than that of other positions and indicated that $\mathrm{SH}$ and $\mathrm{FB}$ move constantly for over $7000 \mathrm{~m}$ per match. SH also performed significantly more SZ-3 (873 m; 12.4\%) and significantly greater acceleration (122 times). SH must always move quickly to the rack during an attack and pass the ball. It is considered that the total distance and the number of accelerations showed a high value due to this characteristic. FB is the most rearward position and must cover a large space during attacks and defenses. It is considered that the total distance has increased due to this characteristic. Also, since these characteristics of $\mathrm{SH}$ and $\mathrm{FB}$ are not greatly affected by wins and losses and match result, $\mathrm{CV}$ also showed a small value.

Regarding the backs, WTBs recorded over $800 \mathrm{~m}$ of SZ-3 and had the highest AZ-3 scores. Thus, WTBs need to be able to sprint repeatedly and require training for improving their maximum speed. On the other hand, CTBs deal with higher impact loads than other backs. When creating a training programme for CTBs, it is necessary to incorporate more contact fitness with repeated tackles and down-up operations.

This study objectively visualised the physical demands of rugby union matches and supported the empirical observations coaches had identified through their experiences. Overall, the interpretation of data obtained from the GPS unit is yet to be undertaken, and the new possibilities for analysis with the use of GPS units that this invites are unlimited. Additional research is required to qualitatively analyse the data obtained from the GPS units.

\section{CONCLUSION}

Differences in the type of physical demands on the forwards and backs were demonstrated, indicating the necessity for specialised training according to the role of the players as well as their specific positions. $\mathrm{SH}$ and FB should be provided training programme with high load, but SH additionally should be given more high-intensity exercise (eg, repeated sprint). Guidelines can be developed according to these results to optimise training programme for each position. Finally, other ideas on how to implement this in actual sports are shown in tables 3 and 4 .
Acknowledgements The authors would like to thank Dr. Takemura for his expert statistical help and Enago (www.enago.com) for the English language review.

Contributors All authors were involved in the conceptualisation, design and conduction of the study. All authors were involved in the drafting and revision of the manuscript for intellectual content, and all approved the final version of the article. HY and TH planned the study. HY conducted a survey. MT conducted statistical analysis. Jl and JT helped with the writing of the paper. MT proofreads English.

Funding The authors have not declared a specific grant for this research from any funding agency in the public, commercial or not-for-profit sectors.

Competing interests None declared.

Patient consent for publication Not required.

Ethics approval This study was approved by the Ethics Committee of Doshisha University (approval number 17084).

Provenance and peer review Not commissioned; externally peer reviewed.

Data availability statement Data are available on reasonable request.

Open access This is an open access article distributed in accordance with the Creative Commons Attribution Non Commercial (CC BY-NC 4.0) license, which permits others to distribute, remix, adapt, build upon this work non-commercially, and license their derivative works on different terms, provided the original work is properly cited, appropriate credit is given, any changes made indicated, and the use is non-commercial. See: http://creativecommons.org/licenses/by-nc/4.0/.

ORCID iD

Hayato Yamamoto http://orcid.org/0000-0002-2578-2526

\section{REFERENCES}

1 Nicholas CW. Anthropometric and physiological characteristics of rugby Union football players. Sports Med 1997;23:375-96.

2 Austin D, Gabbett T, Jenkins D. The physical demands of super 14 rugby Union. J Sci Med Sport 2011;14:259-63.

3 Austin D, Gabbett T, Jenkins D. Repeated high-intensity exercise in professional rugby Union. J Sports Sci 2011;29:1105-12.

4 Deutsch MU, Kearney GA, Rehrer NJ. Time - motion analysis of professional rugby union players during match-play. J Sports Sci 2007;25:461-72.

5 Eaton C, George K. Position specific rehabilitation for rugby union players. Part I: empirical movement analysis data. Physical Therapy in Sport 2006;7:22-9.

6 McLean DA. Analysis of the physical demands of international rugby Union. J Sports Sci 1992;10:285-96.

7 Roberts SP, Trewartha G, Higgitt RJ, et al. The physical demands of elite English rugby Union. J Sports Sci 2008;26:825-33.

8 Cunniffe B, Proctor W, Baker JS, et al. An evaluation of the physiological demands of elite rugby Union using global positioning system tracking software. J Strength Cond Res 2009;23:1195-203.

9 Dobson BP, Keogh JWL. Methodological issues for the application of time-motion analysis research. Strength Cond J 2007;29:48-55.

10 Coutts AJ, Duffield R. Validity and reliability of GPs devices for measuring movement demands of team sports. J Sci Med Sport 2010;13:133-5.

11 Varley MC, Fairweather IH, Aughey RJ. Validity and reliability of GPs for measuring instantaneous velocity during acceleration, deceleration, and constant motion. J Sports Sci 2012;30:121-7.

12 Jennings D, Cormack S, Coutts AJ, et al. The validity and reliability of GPs units for measuring distance in team sport specific running patterns. Int J Sports Physiol Perform 2010;5:328-41.

13 Petersen C, Pyne D, Portus M, et al. Validity and reliability of GPs units to monitor cricket-specific movement patterns. Int J Sports Physiol Perform 2009;4:381-93.

14 Waldron $\mathrm{M}$, Worsfold $\mathrm{P}$, Twist $\mathrm{C}$, et al. Concurrent validity and test-retest reliability of a global positioning system (GPs) and timing gates to assess sprint performance variables. J Sports Sci 2011;29:1613-9.

15 Gregson W, Drust B, Atkinson G, et al. Match-to-match variability of high-speed activities in premier League soccer. Int J Sports Med 2010;31:237-42.

16 Scott BR, Lockie RG, Knight TJ, et al. A comparison of methods to quantify the in-season training load of professional soccer players. Int J Sports Physiol Perform 2013;8:195-202.

17 Jennings D, Cormack SJ, Coutts AJ, et al. Gps analysis of an international field hockey tournament. Int J Sports Physiol Perform 2012;7:224-31. 
18 Macutkiewicz D, Sunderland C. The use of GPs to evaluate activity profiles of elite women hockey players during match-play. J Sports Sci 2011;29:967-73.

19 Gabbett TJ, Jenkins DG, Abernethy B. Physical demands of professional rugby League training and competition using microtechnology. J Sci Med Sport 2012;15:80-6.

20 Kempton T, Sirotic AC, Coutts AJ. Between match variation in professional rugby League competition. J Sci Med Sport 2014;17:404-7.

21 Colby MJ, Dawson B, Heasman J, et al. Accelerometer and GPSderived running loads and injury risk in elite Australian footballers. $J$ Strength Cond Res 2014;28:2244-52.

22 Wisbey B, Montgomery PG, Pyne DB, et al. Quantifying movement demands of AFL football using GPs tracking. J Sci Med Sport 2010;13:531-6.

23 Cahill N, Lamb K, Worsfold P, et al. The movement characteristics of English Premiership rugby union players. J Sports Sci 2013;31:229-37.

24 Coughlan GF, Green BS, Pook PT, et al. Physical game demands in elite rugby Union: a global positioning system analysis and possible implications for rehabilitation. $J$ Orthop Sports Phys Ther 2011;41:600-5.

25 Jones MR, West DJ, Crewther BT, et al. Quantifying positional and temporal movement patterns in professional rugby Union using global positioning system. Eur J Sport Sci 2015;15:488-96.

26 McLaren SJ, Weston M, Smith A, et al. Variability of physical performance and player match loads in professional rugby Union. $J$ Sci Med Sport 2016;19:493-7.

27 Yamamoto $\mathrm{H}$, Takemura M, Kaya M, et al. Physical demands of elite rugby Union match-play using global positioning system. Football Sci 2017;14:15-23.

28 Bataller-Cervero AV, Gutierrez H, DeRentería J, et al. Validity and reliability of a $10 \mathrm{~Hz}$ GPs for assessing variable and mean running speed. J Hum Kinet 2019;67:17-24.

29 Yamamoto H, Takemura M, Tachibana M, et al. Game analysis of rugby Union using GPs. Jpn J Biomecha Sports Exer 2017;21:25-9.

30 Furukawa T, Washiya K, Koyanagi R, et al. Practical applications and possibility of GPs technology in rugby coaching. Jpa J Coaching Studies 2013;26:187-96. 